\title{
Reconstituição cirúrgica do períneo após o parto: um estudo qualitativo de uma prática pedagógica
}

\author{
Surgical reconstitution of the perineum after delivery: \\ a qualitative study of a pedagogical practice
}

Luísa Sotto-Mayor (https://orcid.org/0000-0001-6509-2645) ${ }^{1}$

Maria Anabela Ferreira dos Santos (https://orcid.org/0000-0002-1675-5227) ${ }^{1}$

Irene Maria Trindade Soares (https://orcid.org/0000-0002-9250-0349) ${ }^{1}$

Maria Teresa Santana Félix (https://orcid.org/0000-0003-0745-0648) ${ }^{1}$

Maria João Delgado (https://orcid.org/0000-0001-6956-6414) ${ }^{1}$

Isabel Maria Guerra Gordinho de Rogado Serra (https://orcid.org/0000-0002-3617-6695) ${ }^{1}$

${ }^{1}$ Departamento de Enfermagem de Saúde Materna, Escola Superior de Enfermagem de Lisboa. Av. Prof. Egas Moniz. 1600-096 Lisboa Portugal. mlpinto@esel.pt

\begin{abstract}
A pedagogical activity with Master's Degree and Postgraduate students in Maternal Health and Obstetrics Nursing is described, applying principles of simulated practice in perineal suturing after delivery. This procedure causes a lot of insecurity and generates great anxiety in the students, when they start the internship in a delivery room. Objectives: to develop the psychomotor skills in students for perineal surgical reconstruction; increase students' self-confidence to perform the procedure. Methodology: qualitative, with 2 moments of data collection applied to two courses. Questionnaire with open questions, focus group session and filming. Content analysis of the answers to the questions and verbatim of the focus group. Results: a close relationship was observed between simulation and skills development. Conclusion: the students emphasized the importance of the pedagogical activity in the acquisition of suturing skills, improving their self-confidence and reducing the initial anxiety. The use of the qualitative research allowed identifying the impact of the simulated practice on the development of the students' skills and to identify aspects to be improved, contributing to the progress of pedagogical practices.
\end{abstract}

Key words Simulation, Suturing techniques, Perineum, Students, Obstetric nursing
Resumo Descreve-se uma atividade pedagógica com estudantes do Mestrado e Pós-Licenciatura em Enfermagem de Saúde Materna e Obstetrícia, aplicando princípios da prática simulada na realização da sutura perineal após o parto. Este procedimento causa muita insegurança e gera grande ansiedade nos estudantes, quando iniciam estágio em bloco de partos. Os objetivos deste artigo são desenvolver competências psicomotoras nos estudantes para a reconstituição cirúrgica perineal; aumentar a autoconfiança dos estudantes para o procedimento. Metodologia qualitativa, com 2 momentos de recolha de dados aplicados a dois cursos. Questionário com perguntas abertas, sessão de "focus group" e filmagem. Análise de conteúdo das respostas às perguntas abertas e verbatim do "focus group". Como Resultados destaca-se uma estreita relação entre a simulação e o desenvolvimento de competências. Os estudantes salientaram a importância da atividade pedagógica na aquisição de competências de sutura, reforço da autoconfiança e na diminuição da ansiedade inicial. O uso da investigação qualitativa permitiu identificar o impacto da prática simulada no desenvolvimento de competências dos estudantes, identificar aspetos a aperfeiçoar na metodologia, contribuindo para a melhoria das práticas pedagógicas.

Palavras-chave Simulação, Técnicas de Sutura, Períneo, Estudantes, Enfermagem Obstétrica 


\section{Introdução}

A prática simulada (PS) é considerada um recurso pedagógico fundamental na formação de profissionais de saúde e a importância deste tipo de métodos de ensino-aprendizagem tem sido comprovada em vários estudos ${ }^{1,2}$.

A preocupação crescente, a nível mundial, relacionada com as questões éticas e de segurança, decorrentes da formação prática dos estudantes em contexto real, torna estas metodologias mais atrativas, permitindo atingir os resultados de aprendizagem sem prejuízo para os clientes e com ganhos em saúde 3 .

Os estudantes dos Cursos de Mestrado e de Pós-Licenciatura de Especialização em Enfermagem de Saúde Materna e Obstetrícia (CMESMO e CPLEESMO) devem aprofundar e desenvolver competências durante o seu percurso formativo, de uma forma adequada e segura, quer para si próprios quer para as parturientes 4 .

O estudante deve ter em conta o seu bem -estar e apropriar-se da relevância desse mesmo bem-estar no cuidado à parturiente. Tal tem sido o foco da atenção dos docentes/enfermeiros especialistas em saúde materna e obstétrica (EES$\mathrm{MO}$ ).

Assim sendo, a orientação pedagógica durante a PS assentou nos pressupostos da teoria de Swanson, inerente aos processos de cuidar: conhecer cada estudante, estar com ele presencial e emocionalmente, fazer por, demonstrando quando este referisse dificuldades, preservando a sua dignidade, de modo a possibilitar uma evolução técnica, mantendo a crença no seu potencial para ultrapassar a situação, atingir os resultados esperados e enfrentar o futuro de forma significativa $^{5,6}$.

Apesar das orientações da OMS, desde 1996, no sentido da redução da taxa de episiotomia, em mulheres com parto vaginal espontâneo ${ }^{7}$, a sutura perineal (pós episiotomia ou laceração) é uma intervenção frequente do EESMO na prática de cuidados.

\section{Prática Simulada de Baixa-fidelidade - uma estratégia de formação em sutura perineal}

O treino através da prática simulada de altafidelidade é complexificado pelo elevado custo financeiro que acarreta, pelo que o recurso à prática simulada de média ou baixa fidelidade permite que, com menores custos, algumas competências como as da reparação cirúrgica do períneo sejam apreendidas.
Adquirir conhecimentos teóricos, através de sessões letivas ou pesquisa bibliográfica, não permite ao estudante atingir o nível adequado e necessário ao seu desempenho futuro enquanto enfermeiro obstetra. Para isso, deve articular e complementar esses conhecimentos com práticas clínicas, que decorrem em contexto de ensino clínico em bloco de partos. É importante que, antes de iniciar o estágio, experiencie a prática simulada em contexto controlado, uma vez que a aprendizagem desenvolvida com parturientes é condicionada por aspetos ético-legais.

A aprendizagem através da prática simulada tem demonstrado ser uma excelente estratégia para os estudantes adquirirem e/ou desenvolverem capacidades antes de as mobilizarem e aperfeiçoarem na prática clínica. Permite também o treino e a reflexão sobre a ação e para a ação ${ }^{3,8}$.

O treino baseado na simulação é ideal para desenvolver habilidades instrumentais, como os procedimentos cirúrgicos básicos de sutura do períneo (episiorrafia e perineorrafia), revelando um impacto benéfico na autoconfiança, satisfação e autoeficácia ${ }^{1,9}$.

\section{Metodologia}

A atividade pedagógica, sobre a qual recai este estudo, foi realizada no âmbito da unidade curricular Estágio com Relatório, que decorre no $4^{\circ}$ semestre do $8^{\circ}$ CMESMO e do $9^{\circ}$ CPLEESMO, que se realiza em contexto de bloco de partos. É um treino de baixa-fidelidade autodirigido, com a orientação e feedback permanente de um professor.

Teve como ponto de partida a resposta à seguinte questão de investigação: "como percecionam os estudantes do CMESMO e CPLEESMO os contributos da prática simulada no desenvolvimento de competências psicomotoras para a reconstituição cirúrgica do períneo/sutura?"

Pretendeu-se dar resposta a dois objetivos: 1. desenvolver competências psicomotoras nos estudantes para executarem a episiorrafia; 2 . aumentar a autoconfiança dos estudantes para o desempenho do procedimento.

Realizou-se um estudo exploratório descritivo de abordagem qualitativa, com vários momentos e diversos métodos de recolha de dados, de forma a obter resultados mais consistentes, como descreveremos adiante.

Pretende-se que o estudante possa desenvolver, em ambiente controlado, competências que lhe permitam melhorar o desempenho em con- 
texto real, quer na vertente técnica, como na psicológica, cognitiva e atitudinal ${ }^{1}$.

Os participantes desta atividade pedagógica foram 18 estudantes do CMESMO e 15 do CPLEESMO, no último semestre dos respetivos cursos, maioritariamente do sexo feminino, à exceção de dois. Todos detinham uma experiência anterior mínima de 2 anos como enfermeiros de cuidados gerais à data do início do curso. Os estudantes foram informados sobre os objetivos do estudo e foi-lhes solicitado o consentimento informado para a captação e o uso de fotos e vídeo, bem como para a utilização das narrativas manifestadas durante a sessão de focus group e das respostas às questões abertas.

Esta atividade de prática simulada de baixa fidelidade foi composta por 3 sessões. A primeira de 2 horas e as seguintes de 3 horas cada, que decorreram durante uma semana. Os estudantes foram divididos em grupos de 3, tendo cada estudante 3 sessões com orientação presencial de um docente.

Para ambos os cursos, a primeira sessão foi composta por formação teórica que visava rever conteúdos teóricos anteriormente lecionados. A primeira sessão inclui o treino do nó cirúrgico, manuseamento dos instrumentos cirúrgicos (porta agulhas, pinça e tesoura), e a iniciação à sutura em "modelo de bancada em espuma de alta densidade". Na segunda sessão deu-se continuidade ao treino no modelo referido. Na terceira sessão foi realizado o treino da reconstituição do períneo, em "modelo de bancada de peça de carne", conforme Figuras 1 e 2.
O estudante aprende e treina, em ordem crescente de complexidade, a técnica do "nó cirúrgico", a sutura de pontos separados - o "ponto simples", o ponto separado vertical ou em ' $U$ ' o "ponto Donatti", e a "sutura contínua", aperfeiçoando os nós e as suturas. Foram utilizados os fios de sutura: Novosyn ${ }^{\circledR}$ Quick HR37s, 0, e Novosyn ${ }^{\circledR}$ Quick HR37, 2-0, utilizados habitualmente nas salas de parto em Portugal.

Embora houvesse uma linha condutora do processo ensino-aprendizagem comum, este considerou as necessidades específicas de cada estudante, a sua destreza ou dificuldades apresentadas. A prática foi individualizada, repetitiva e participativa. O "modelo de bancada de espuma de alta densidade" é composto por uma tábua de madeira com um paralelepípedo de espuma de cerca de $15 \mathrm{~cm}$ x $15 \mathrm{~cm}$ x $10 \mathrm{~cm}$, amovível e suportado por dois ganchos metálicos e um elástico, para impedir que o bloco de espuma deslize durante o procedimento. O "modelo de bancada com peça de carne”, composto por uma tábua de madeira, um resguardo descartável impermeável e uma pinça de Kocher, permite fixar a peça de carne, impedindo a sua mobilização aquando do treino. A carne é geralmente de suíno, sendo as peças mais utilizadas a entremeada ou o lombo. Este tipo de peças permite uma melhor simulação das estruturas anatómicas após episiotomia ou laceração perineal (sendo utilizada uma lâmina de bisturi para reproduzir essas lesões), possibilitando uma melhor percepção das diferentes estruturas, tais como a mucosa, a transição para a pele, o tecido celular subcutâneo e o músculo. Há
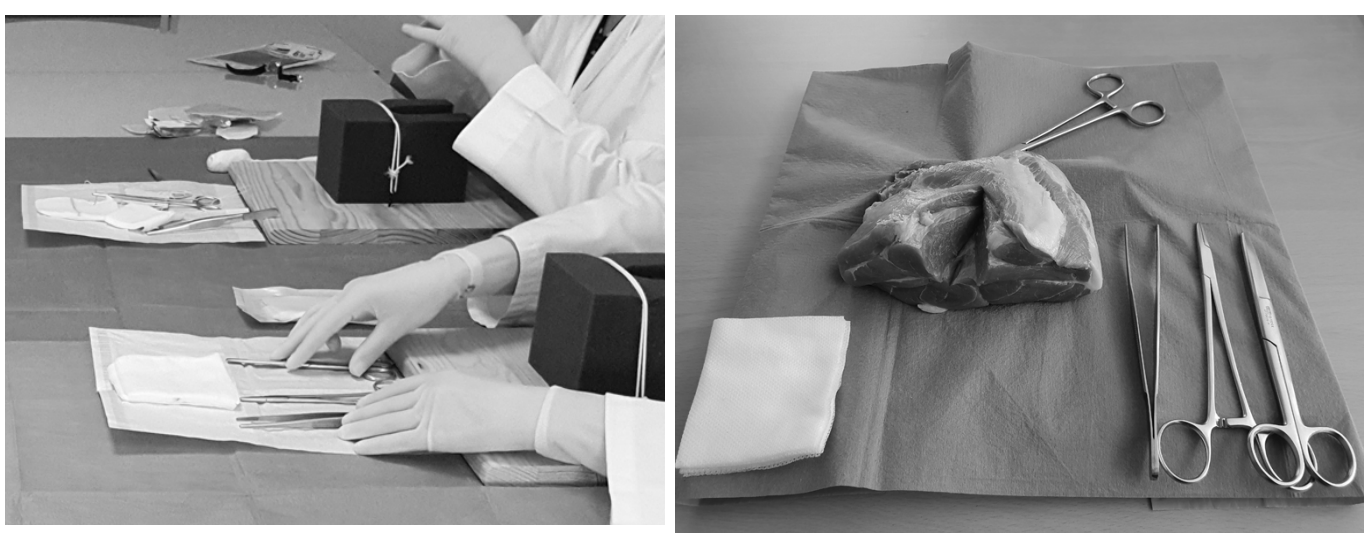

Figuras 1 e 2. Equipamento utilizado para treino de iniciação à sutura. 
assim a possibilidade de um treino mais eficaz e real da coaptação dos bordos da "ferida".

As perguntas abertas do questionário realizado ao CMESMO, em 2018, antes de iniciarem o estágio, foram as seguintes:

1. De uma forma sucinta mencione 3 aspectos que considera mais positivos/facilitadores na/ da sua participação nesta formação;

2. De uma forma sucinta mencione 3 aspectos que considera menos positivos/dificultadores na/da sua participação nesta formação;

3. Para poder melhorar esta prática formativa como instrumento do processo de ensino-treino de aprendizagem que sugestão/ões apresentaria?

$\mathrm{Na}$ sessão de focus group validou-se toda a informação obtida anteriormente. Pretendia-se que identificassem as dificuldades iniciais e as confrontassem com a evolução no domínio da técnica. Para tal, foram colocadas as seguintes questões:

a. Que competências desenvolveu com esta atividade pedagógica?

b. Que facilidades/aspectos facilitadores encontrou no decurso desta atividade?

c. Que dificuldades/aspectos dificultadores encontrou no decurso desta atividade?

d. Que sugestões faz para que esta atividade possa ser melhorada?

A sessão de focus group foi filmada e gravada em áudio e transcrito o seu verbatim, para ser posteriormente analisado.

Com o intuito de validar a importância da experiência pedagógica formulamos a seguinte questão, que foi apresentada ao 9o CPLEESMO em 2019, no final do estágio: "descreva de que forma as sessões de prática simulada de iniciação à sutura contribuíram para a aquisição da competência de reconstituição cirúrgica do períneo?”

Foi sujeito a uma análise de conteúdo, segundo Bardin $^{10}$, todo o material recolhido através dos vários métodos de recolha de dados já mencionados (perguntas abertas do questionário e verbatim do focus group ${ }^{11}$ ).

\section{Resultados e discussão}

Os estudantes que participaram na atividade destacaram, em ambos os momentos (durante a PS e no final do estágio) o contributo da PS para a segurança da parturiente/estudante, para o desenvolvimento de competências ao nível cognitivo, instrumental e afetivo. Durante a PS, emergiu a gestão temporal, do espaço de intervenção e a oportunidade de vivenciar e antecipar facilidades e dificuldades, bem como a reflexão sobre a prática de cuidados.

As categorias que emergiram das respostas às questões formuladas aos estudantes, foram: facilidades e dificuldades percepcionadas, competências adquiridas e sugestões (no primeiro momento durante a PS); e no segundo, no final do estágio: o processo ensino-aprendizagem e os domínios cognitivo, psicomotor e afetivo.

Nos quadros, referentes às categorias, ilustram-se as subcategorias identificadas com uma unidade de registo considerada pelos autores como a mais significativa da produção verbal dos estudantes.

Na primeira categoria (Quadro 1), as Facilidades Percepcionadas pelos estudantes vão ao encontro da evidência científica, nomeadamente a "Diminuição da ansiedade".

O realismo proporcionado pela simulação foi salientado pelos estudantes como facilitador da "Antecipação da realidade", principalmente quando no treino de sutura foi utilizada uma peça de carne (Figura 3), simulando uma situação similar à de contexto de estágio. A utilização do modelo de espuma de alta densidade, embora não tão apreciado pelos estudantes, permite, no entanto, pôr em prática os passos necessários à reconstrução do períneo (Figuras 4 e 5).

O realismo dos simuladores contribuiu para a satisfação, autoeficácia e autoconfiança dos estudantes, opinião também defendida por Baptista et al. ${ }^{12}$.

Os estudantes manifestaram que a prática simulada lhes permitiu diminuir a ansiedade e o nervosismo que perspetivavam no confronto das situações reais, o que lhes aumentou a autoconfiança, aspectos corroborados por Zapko et al. ${ }^{13}$, que relacionam a diminuição da ansiedade dos estudantes com a prática simulada.

Enquanto estratégia de aprendizagem, os estudantes referiram ainda a importância de reverem e consolidarem conteúdos teóricos lecionados anteriormente para os mobilizar nas situações em simulação. A tomada de consciência da necessidade de aprofundar os conhecimentos teóricos, assim como a motivação e a iniciativa demonstrada, revela que a simulação é uma metodologia adequada para a formação de adultos, quer pela dinâmica ativa de resolução de problemas dos contextos das práticas clínicas ${ }^{14}$, como também pelo envolvimento e responsabilização do estudante na sua própria aprendizagem, num ambiente promotor de bem-estar ${ }^{5,6}$.

Da análise do Quadro 2, referente à categoria Dificuldades Percepcionadas, foram identificadas 
Quadro 1. Principais facilidades percecionadas pelos estudantes.

\begin{tabular}{|l|l|l|c|}
\hline \multicolumn{1}{|c|}{ Categoria } & \multicolumn{1}{|c|}{ Subcategorias } & \multicolumn{1}{c|}{ Unidades de registo } & $\begin{array}{c}\text { Unidades } \\
\text { Frequência }\end{array}$ \\
\hline $\begin{array}{l}\text { Facilidades } \\
\text { Percecionadas }\end{array}$ & Antecipação da realidade & $\begin{array}{l}\text { Deu para ter uma noção mais clara do } \\
\text { que vou ter que fazer }\end{array}$ & 3 \\
\cline { 2 - 4 } & $\begin{array}{l}\text { Observação/Treino anterior } \\
\text { em sutura }\end{array}$ & $\begin{array}{l}\text { Já tinha trabalhado numa área onde } \\
\text { estávamos habituados a ver suturas }\end{array}$ & 3 \\
\cline { 2 - 4 } & $\begin{array}{l}\text { Utilização de Modelo } \\
\text { Biológico (bancada de carne) }\end{array}$ & $\begin{array}{l}\text { A peça de carne simula melhor a } \\
\text { realidade com que nos vamos deparar }\end{array}$ & 3 \\
\cline { 2 - 4 } & Diminuição da ansiedade & $\begin{array}{l}\text { Se não tivéssemos tido estas aulas } \\
\text { iria ser uma sobrecarga maior de } \\
\text { nervosismo }\end{array}$ & 1 \\
\cline { 2 - 4 } & $\begin{array}{l}\text { Mobilização de conhecimentos } \\
\text { teóricos }\end{array}$ & É sempre bom recapitular as bases & 1 \\
\hline
\end{tabular}
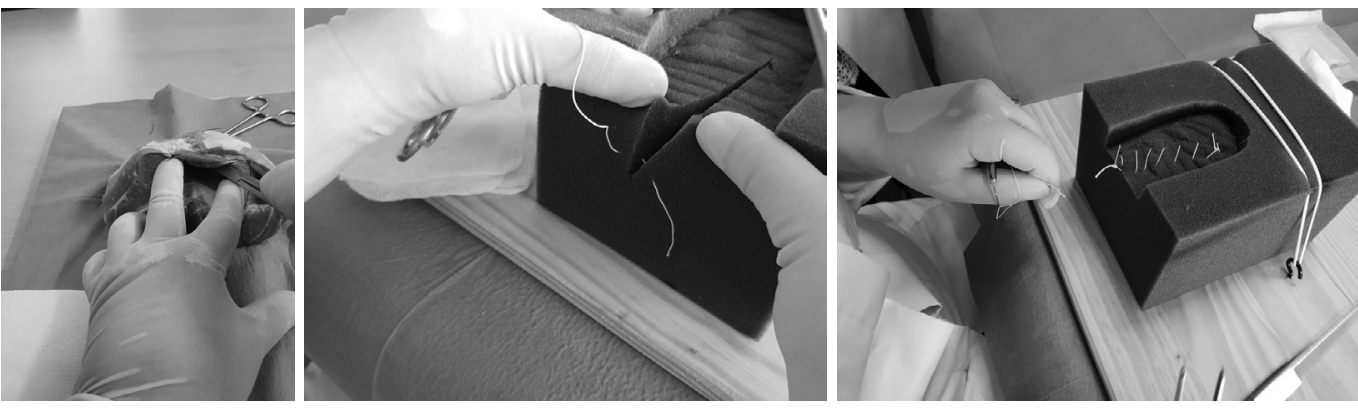

Figuras 3 a 5. Os vários passos do procedimento.

Fonte: fotografias das autoras.

as seguintes subcategorias: "Fidelidade do modelo de bancada de espuma de alta densidade", "Adaptação ao espaço/localização do local a suturar (períneo)", "Manuseamento dos instrumentos cirúrgicos", "Respeito pelos princípios de segurança”, "Reconhecimento das estruturas perineais", "Execução da técnica com rigor" e "Primeiro contacto prático com a técnica".

As dificuldades identificadas pelos estudantes centraram-se na utilização e no manuseamento dos materiais, bem como na adaptação ao espaço disponível para a execução da técnica em contexto real. As dificuldades mencionadas vão ao encontro da experiência docente dos autores, tendo sido um dos pontos de partida para a realização do presente estudo. A percepção destas dificuldades permitirá à equipe docente encontrar estratégias de resolução assentes nos processos de cuidar de Swanson ${ }^{5,6}$, facilitadores da adaptação à prática clínica.

Como vantagens da simulação, para os estudantes, evidencia-se a reflexão e o desenvolvimento do pensamento crítico sobre as suas próprias experiências, a importância de manter a segurança durante os procedimentos ${ }^{15,16}$, de modo a que a possibilidade de ocorrência de erros em contexto real se minimize, aspecto revelador de consciência ética ${ }^{3}$. A possibilidade de ter um primeiro contacto com a técnica, reduzindo deste modo a lacuna entre a teoria e a prática referida pelos estudantes, é corroborada por Joset ${ }^{17}$ e Carneiro et al. ${ }^{18}$.

$\mathrm{Na}$ terceira categoria, Competências Adquiridas, emergiram as subcategorias identificadas no Quadro 3. A perceção das competências adquiridas está em consonância com os objetivos 


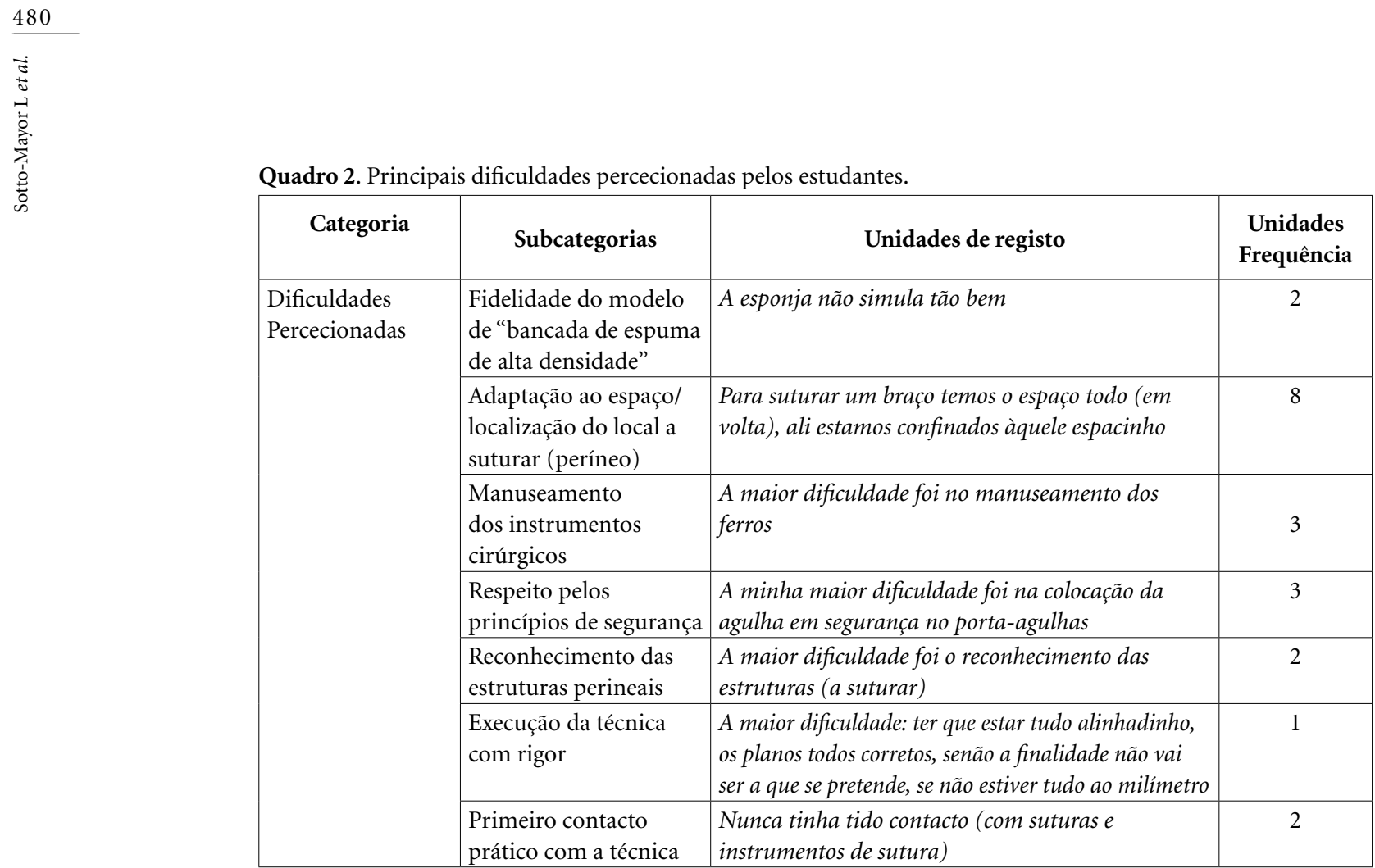

Quadro 3. Competências adquiridas pelos estudantes.

\begin{tabular}{|l|l|l|c|}
\hline \multicolumn{1}{|c|}{ Categoria } & \multicolumn{1}{|c|}{ Subcategorias } & \multicolumn{1}{|c|}{ Unidades de registo } & $\begin{array}{c}\text { Unidades } \\
\text { Frequência }\end{array}$ \\
\hline $\begin{array}{l}\text { Competências } \\
\text { Adquiridas }\end{array}$ & Perceção do risco & $\begin{array}{l}\text { Tomei consciência do risco que corro se não } \\
\text { tomar determinadas precauções }\end{array}$ & 6 \\
\cline { 2 - 4 } & $\begin{array}{l}\text { Desenvolvimento de } \\
\text { autoconfiança }\end{array}$ & $\begin{array}{l}\text { Eu já estava a pensar: depois como é que eu pego } \\
\text { na tesoura, e como é que eu pego na pinça... e } \\
\text { assim deparamo-nos com as coisas e não é tão } \\
\text { complexo como imaginávamos que iria ser }\end{array}$ & 4 \\
\cline { 2 - 4 } & $\begin{array}{l}\text { Desenvolvimento da } \\
\text { destreza manual }\end{array}$ & $\begin{array}{l}\text { Ajuda a nível da destreza com o material e dos } \\
\text { ferros, onde pomos e onde é que não pomos, de } \\
\text { que forma é que abordamos a pele }\end{array}$ & 4 \\
\cline { 2 - 4 } & Adaptação à técnica & $\begin{array}{l}\text { Permite a adaptação ao espaço confinado que } \\
\text { temos para trabalhar }\end{array}$ & 4 \\
\cline { 2 - 4 } & $\begin{array}{l}\text { Aprofundar e mobilizar } \\
\text { os conhecimentos sobre } \\
\text { a técnica }\end{array}$ & $\begin{array}{l}\text { Conhecimento dos vários tipos de pontos e dos } \\
\text { vários tipos de planos, e como é que se deve } \\
\text { executar }\end{array}$ & 3 \\
\hline
\end{tabular}

desta atividade pedagógica, nomeadamente o desenvolvimento de competências psicomotoras e o aumento da autoconfiança dos estudantes para o desempenho do procedimento. São disso exemplo as subcategorias identificadas e as unidades de registo apresentadas, corroboradas por outros autores, reveladoras do desenvolvimento do pensamento crítico ${ }^{12}$, das competências éticas envolvidas na promoção de um ambiente seguro $^{8,15,19,20}$, do aumento da autoconfiança, da diminuição da ansiedade, da redução das lacunas entre a teoria e a prática, que traduzem um incremento das competências psicomotoras ${ }^{8}$. A estreita relação entre a simulação e o desenvolvimento de competências, patente na evidência científica, é salientada por Dimassi et al. ${ }^{21}$.

Na última categoria, Sugestões, cujas subcategorias se apresentam no Quadro 4, verifica-se que estas recaem sobre a necessidade de aumentar o tempo disponibilizado na semana de prática simulada para a atividade de reconstituição cirúrgica do períneo, a utilização do modelo biológico 
Quadro 4. Sugestões para a melhoria da atividade identificadas pelos estudantes.

\begin{tabular}{|l|l|l|c|}
\hline \multicolumn{1}{|c|}{ Categoria } & \multicolumn{1}{|c|}{ Subcategorias } & \multicolumn{1}{|c|}{ Unidades de registo } & $\begin{array}{c}\text { Unidades } \\
\text { Frequência }\end{array}$ \\
\hline \multirow{5}{*}{ Sugestões } & $\begin{array}{l}\text { Utilização do Modelo Biológico } \\
\text { desde o início, que simule diferentes } \\
\text { estruturas }\end{array}$ & $\begin{array}{l}\text { Com um modelo de carne a experiência é } \\
\text { mais real, e suscita-nos mais dúvidas }\end{array}$ & 6 \\
\cline { 2 - 4 } & $\begin{array}{l}\text { Aumentar o tempo desta atividade } \\
\text { formativa }\end{array}$ & $\begin{array}{l}\text { O tempo (desta atividade) deveria ser } \\
\text { mais prolongado }\end{array}$ & 11 \\
\cline { 2 - 4 } & $\begin{array}{l}\text { Aumentar o rácio professor/ } \\
\text { estudante }\end{array}$ & $\begin{array}{l}\text { Deveria haver mais professores nessa } \\
\text { atividade }\end{array}$ & 4 \\
\cline { 2 - 4 } & $\begin{array}{l}\text { Manter o mesmo grupo de } \\
\text { estudantes nas diferentes sessões }\end{array}$ & $\begin{array}{l}\text { Deveria ser um dia completo, de manhã } \\
\text { e de tarde, sempre as mesmas pessoas }\end{array}$ & 1 \\
\cline { 2 - 4 } & $\begin{array}{l}\text { Fornecimento da "peça de carne" } \\
\text { pela Escola }\end{array}$ & $\begin{array}{l}\text { O equipamento que a ESEL forneceu } \\
\text { foi o adequado, mas poderia também } \\
\text { fornecer a peça de carne }\end{array}$ & 2 \\
\cline { 2 - 4 } & $\begin{array}{l}\text { Não intercalar outras atividades de } \\
\text { prática simulada }\end{array}$ & $\begin{array}{l}\text { Torna-se 'baralhado' andar sempre a } \\
\text { trocar de atividade }\end{array}$ & 3 \\
\cline { 2 - 4 } & $\begin{array}{l}\text { Utilização de modelo mais próximo } \\
\text { da realidade (dimensão do corpo da } \\
\text { puérpera) }\end{array}$ & $\begin{array}{l}\text { O modelo (deveria) ser mais real, e que } \\
\text { tenha pernas (para melhor simular o } \\
\text { espaço disponivel) }\end{array}$ & 3 \\
\hline
\end{tabular}

desde a primeira sessão prática, o aumento do rácio professor/estudante, e também a utilização de um modelo mais próximo da realidade do corpo da puérpera. Esta última sugestão permitiria ao estudante ter uma melhor noção do espaço real para a reconstrução do períneo no pós-parto. Há outras sugestões interessantes, como por exemplo a sugestão de não intercalar outras atividades com a prática da sutura.

As sugestões apresentadas pelos estudantes são reveladoras da importância que atribuíram à experiência e focam-se essencialmente na necessidade de aumentar o tempo da atividade e de implementar medidas que confiram maior realismo à situação em simulação, como também é defendido por outros autores ${ }^{12}$. Por outro lado, Villalba et al. ${ }^{3}$ salientam as preocupações com a segurança dos clientes e com o facto de os estudantes não "praticarem" neles. Por este motivo, para alguns autores, a utilização da simulação como instrumento para o ensino de enfermagem é apontada como um imperativo ético, uma vez que resulta em vários benefícios para os alunos e para os clientes dos serviços de saúde ${ }^{8,22}$. Por sua vez, Almeida et al. ${ }^{23}$ acrescentam que os bons resultados da prática simulada, enquanto estratégia de ensino aprendizagem, têm demonstrado ser um bom preditor de um nível de desempenho elevado em contexto real.

O Quadro 5, Perceção dos estudantes sobre o contributo da Prática Simulada no final do estágio, enuncia a percepção dos estudantes sobre a
PS, quatro meses após a sua realização, no final do estágio. As categorias que emergiram se assentam nos três domínios de competência (cognitivo, psicomotor e afetivo), conforme é referido na literatura consultada, que enuncia os domínios $\operatorname{cognitivo~}^{22}$, psicomotor $^{24}$ e afetivo $^{9}$. Emerge como relevante a categoria Processo Ensino-Aprendizagem como uma mais valia da PS, tal como referido por Baptista et al. ${ }^{12}$ e Miranda et al..$^{22}$.

A estreita relação entre a simulação e o desenvolvimento de competências parece emergir nestes relatos, tal como salientada na evidência científica $^{25}$.

\section{Conclusões}

A Prática Simulada evidenciou ser uma estratégia pedagógica com elevado potencial na formação dos estudantes.

Esta metodologia permitiu uma aprendizagem centrada no estudante, assente na teoria de cuidar de Swanson, em ambiente controlado e seguro, sustentada no treino repetido e na reflexão sob orientação personalizada do docente.

A realização deste estudo deu resposta à questão de partida. Nos resultados obtidos através das narrativas dos estudantes foi percecionado o contributo desta metodologia para a segurança da parturiente, o desenvolvimento de competências ao nível cognitivo, instrumental, afetivo, a gestão temporal e do espaço de intervenção. Vivenciar e 
Quadro 5. Perceção dos estudantes sobre o contributo da Prática Simulada no final do estágio.

\begin{tabular}{|c|c|c|c|}
\hline Categoria & Subcategorias & Unidades de registo & $\begin{array}{l}\text { Unidades } \\
\text { Frequência }\end{array}$ \\
\hline $\begin{array}{l}\text { Processo ensino- } \\
\text { aprendizagem }\end{array}$ & Importância/Mais valia & $\begin{array}{l}\text { No local de ensino clínico o enfermeiro } \\
\text { orientador também refere um melhor } \\
\text { desempenho dos alunos que tiveram prática } \\
\text { simulada, comparativamente aos que não } \\
\text { tiveram. }\end{array}$ & 8 \\
\hline Domínio Cognitivo & $\begin{array}{l}\text { Aquisição de } \\
\text { conhecimentos teóricos }\end{array}$ & $\begin{array}{l}\text { Permitiu-me adquirir conhecimentos } \\
\text { básicos acerca da técnica }\end{array}$ & 9 \\
\hline \multirow[t]{4}{*}{$\begin{array}{l}\text { Domínio } \\
\text { Psicomotor/ } \\
\text { Instrumental }\end{array}$} & $\begin{array}{l}\text { Aquisição de } \\
\text { competências para a } \\
\text { prática clínica }\end{array}$ & $\begin{array}{l}\text { Contribuiu para a aquisição de } \\
\text { competências na reconstituição do períneo, } \\
\text { pois no momento de realizar a perineorrafia } \\
\text { no ensino clinico já não era novidade }\end{array}$ & 5 \\
\hline & $\begin{array}{l}\text { Treino de destreza } \\
\text { manual/técnica }\end{array}$ & $\begin{array}{l}\text { Pude treinar vários pontos e repeti-los o } \\
\text { suficiente, para na prática não me sentir tão } \\
\text { às cegas' como se nunca tivesse treinado }\end{array}$ & 9 \\
\hline & $\begin{array}{l}\text { Manipulação do material } \\
\text { de sutura }\end{array}$ & $\begin{array}{l}\text { Deu-me a possibilidade de conhecer e } \\
\text { aprender a manipular todo o material de } \\
\text { sutura }\end{array}$ & 5 \\
\hline & Treino de Assepsia & Permitiu treinar para assegurar a assepsia & 2 \\
\hline \multirow[t]{3}{*}{ Domínio Afetiivo } & $\begin{array}{l}\text { Diminuição da ansiedade } \\
\text { no estágio }\end{array}$ & $\begin{array}{l}\text { Por outro lado, o podermos praticar em sala } \\
\text { de aula permite que em contexto de ensino } \\
\text { clínico exista uma menor ansiedade perante } \\
\text { esta prática }\end{array}$ & 1 \\
\hline & $\begin{array}{l}\text { Maior confiança para a } \\
\text { prática em estágio }\end{array}$ & $\begin{array}{l}\text { Possibilitou-me aumentar a minha } \\
\text { confiança no decorrer do estágio com } \\
\text { relatório }\end{array}$ & 1 \\
\hline & $\begin{array}{l}\text { Treino em ambiente } \\
\text { controlado e seguro para } \\
\text { estudante/cliente }\end{array}$ & $\begin{array}{l}\text { Pudemos praticar anteriormente em peça de } \\
\text { carne ou esponja sem trazer problemas para } \\
\text { a mulher. }\end{array}$ & 3 \\
\hline
\end{tabular}

antecipar facilidades e dificuldades perante esta técnica permitiu aos estudantes a reflexão sobre a prática de cuidados e respectiva antecipação.

Para além das competências mencionadas, os estudantes referiram ter desenvolvido o pensamento crítico-reflexivo, a responsabilidade profissional e tomaram consciência das questões éticas envolvidas.

A mais-valia referida pelos estudantes vai ao encontro da percepcionada pelos docentes envolvidos e pelos enfermeiros orientadores em contexto clínico.

As limitações encontradas apontam essencialmente para a necessidade de mais tempo de duração do treino e de um rácio mais elevado professor/aluno.

A realização do presente estudo permitiu dar resposta aos objetivos delineados e promoveu uma reflexão crítica da atividade docente sobre a prática simulada de baixa fidelidade, o que se re- percutirá no futuro em reajustes e adaptações ao planeamento das sessões. Torna-se importante e necessário continuar a investigar esta prática pedagógica, monitorizando e avaliando o impacto deste tipo de metodologia, identificando aspectos a aperfeiçoar, bem como divulgar os resultados destas atividades junto da comunidade científica.

\section{Colaboradores}

L Sotto-Mayor contribuiu com a coleta de dados. MAF Santos contribuiu com a concepção do estudo e revisão final do manuscrito. IMT Soares e IMGGR Serra contribuíram com processamento de dados. MTS Félix e MJ Delgado contribuíram com a fundamentação teórica. 


\section{Referências}

1. Baptista R, Martins J, Pereira M. Construção e validação da Escala de Ganhos Percebidos com a Simulação de Alta-Fidelidade (EGPSA). Revista de Enfermagem Referência 2016; 22(10):29-37.

2. Nyström S, Dahlberg J, Hult H, Abrandt Dahlgren M. Observing of interprofessional collaboration in simulation: A socio-material approach. Journal of Interprofessional Care 2016; 30(6):710-716.

3. Villalba A, Martin M, Rexachs D, Luque E. Computer simulation as a methodology for theoretical learning of clinical skills in nursing. International Journal of Integrated Care 2018; 18(2):A297.

4. Sotto-Mayor L, Santos M, Soares I, Félix M, Delgado M, Serra I. Prática simulada em reconstituição cirúrgica do períneo após o parto: uma atividade pedagógica. In: Atas do Congresso Ibero-Americano de Investigação Qualitativa 2018; Fortaleza. p. 2021-2030.

5. McKelvey M. Finding Meaning Through Kristen Swanson's Caring Behaviors: A Cornerstone of Healing for Nursing Education. Creative Nursing 2018; 24(1):6-11.

6. Swanson K. Empirical development of a middle range theory of caring. Nursing Research 1991; 40(3):161166.

7. World Health Organization (WHO). WHO recommendations: Intrapartum care for a positive childbirth experience. Geneva: WHO; 2018.

8. Eyikara E, Baykara G. The importance of simulation in nursing education. World Journal on Educational Technology: Current Issues 2017; 9(1):2- 7.

9. Duarte H, Sousa P, Dixe M. A simulação de alta-fidelidade no ensino de enfermagem: perceção de aprendizagem, satisfação e autoeficácia dos estudantes de enfermagem. In: Dixe M, Sousa P, Gaspar P. coordenadores. Construindo conhecimento em enfermagem à pessoa em situação crítica. Leiria: Instituto Politécnico de Leiria; 2017. p. 147-160.

10. Bardin L. Análise de Conteúdo. São Paulo: Edições 70/ Almedina; 2016

11. Oates C, Alevizou P. Conducting focus groups for Business and Management students. Thousand Oaks: Sage; 2018.

12. Baptista R, Pereira M, Martins J. Simulação no ensino de graduação em enfermagem: evidências científicas. In: Martins J, Mazzo A, Mendes I, Rodrigues M, organizadores. A simulação no ensino de enfermagem. Coimbra: Unidade de Investigação em Ciências da Saúde, Escola Superior de Enfermagem de Coimbra; 2014. p. 65-80.

13. Zapko K, Ferranto M, Blasiman R, Shelestak D. Evaluating best educational practices, student satisfaction, and self-confidence in simulation: A descriptive study. Nurse Education Today 2018; 60:28-34.

14. Abreu W. Formação e aprendizagem em contexto clínico: fundamentos, teorias e considerações didácticas. Coimbra: Formasau; 2008.

15. Ayed A, Khalaf I. The Outcomes of Integrating High Fidelity Simulation in Nursing Education: An Integrative Review. Open Journal of Nursing 2018; 8:292-302.
16. Ribeiro V, Garbuio D, Zamariolli, C, Eduardo A, Carvalho E. Simulação clínica e treinamento para as Práticas Avançadas de Enfermagem: revisão integrativa, Brasil. Acta Paulista de Enfermagem 2018; 31(6):659-666

17. Joset E. Graduate Nurses' Perception of the Effect of Simulation on Reducing the Theory-Practice Gap. Sage Open Nursing 2019; 5:1-11.

18. Carneiro K, Moraes-Filho I, Santos O, Arantes A, Félis K, Guilherme I, Cangussu D. Simulação realística como instrumento no processo de ensino-aprendizagem de enfermagem. REVISA 2019; 8(3):273-284.

19. Brasil G, Ribeiro L, Mazzo A, Almeida R, Martins J, Fonseca L, Leon C. Utilização de escalas de design e autoconfiança na avaliação da simulação realística materno-infantil. Revista de Enfermagem Referência 2018; IV(19):117-125.

20. Saied HI. The Impact of Simulation on Pediatric Nursing Students' Knowledge, Self-efficacy, Satisfaction, and Confidence. Journal of Education and Practice 2017; 8(11):95-102.

21. Dimassi K, Daiki M, Rafrafi A, Bousselmi R, Ferjani M. Impact of high fidelity simulation on perceptions and professional skills in obstetrics. La Tunisie Medicale 2019; 97(6):771-778.

22. Miranda RPR, Chaves ECL, Lima RS, Braga C, Simões I, Fava S, Iunes D. The effectiveness of a simulated scenario to teach nursing students how to perform a bed bath: A randomized clinical trial. Nurse Education Today 2017; 57:17-23.

23. Almeida R, Mazzo A, Martins J, Jorge B, Souza Júnior VD, Mendes I. Self-confidence in the care of critically ill patients: before and after a simulated intervention. Revista Brasileira de Enfermagem 2019; 72(6):16181623.

24. Ventura, C. (2014). Ética e simulação em enfermagem. In: Martins J, Mazzo A, Mendes I, Rodrigues M, organizadores. A simulação no ensino de enfermagem. Coimbra: Unidade de Investigação em Ciências da Saúde, Escola Superior de Enfermagem de Coimbra; 2014. p. 29-38.

25. Gonçalves R, Coutinho V, Lobão, C. Simulação e desenvolvimento de competências. In: Martins J, Mazzo A, Mendes I, Rodrigues M, organizadores. A simulação no ensino de enfermagem. Coimbra: Unidade de Investigação em Ciências da Saúde, Escola Superior de Enfermagem de Coimbra; 2014. p. 125-133.

Artigo apresentado em 07/04/2020

Aprovado em 20/05/2020

Versão final apresentada em 22/05/2020

Editores chefes: Maria Cecília de Souza Minayo, Romeu Gomes, Antônio Augusto Moura da Silva 
